\section{The Modern Chemist}

must keep up-to-date on all advances in chemistry, not only in his own special field

- cannot possibly read all the scientific journals which publish original experimental work their number is too great and he does not have the time

- must rely on review articles from which he can learn of new developments in all fields of chemistry

\title{
ANGEWANDTE CHEMIE \\ International Edition in English
}

presents

- review articles from all fields of chemistry, written by authorities, concise, easy to read, with guiding literature references,

and in addition

- short communications from all fields of chemical research, carefully selected to assure highest standards

- conference reports and abstracts of lectures given at the most important European chemical meetings, covering unpublished results

selected abstracts reporting the highlights from the international chemical literature

book reviews

Review articles to be published in Volume 3, 1964

E. Bayer et al., Tübingen (Germany)

Structure and Specificity of Organic Complexing Agents

K. Heusler et al., Basel (Switzerland)

Intramolecular Radical Reactions
P. Jollès, Paris (France)

Recent Developments in the Study of Lysozymes

R. Juza, Kiel (Germany)

Amides of the Alkali and Alkaline Earth Metals

E. Lederer, Gif-Sur-Yvette (France)

Biogenesis, Structure and Biological Effects of the Lipids of Mycobacterium tuberculosis

F. W. Lichtenthaler, Darmstadt (Germany)

Cyclization of Dialdehydes with Nitromethane

M. Schlosser, Heidelberg (Germany)

Organosodium and Organopotassium Compounds

G. N. Schrauzer, Munich (Germany)

Co-ordination Chemistry and Catalysis

K. Schwabe, Dresden (Germany)

Theories of the Glass Electrode

M. M. Shemyakin et al., Moscow (U.S.S.R.)

Synthesis of Naturally Occurring Unsaturated Fatty Acids by Sterically Controlled Carbonyl Olefination

G. Sosnovsky et al., Chicago, Illinois (U.S.A.)

The Perester Reaction

H. Zimmermann, Munich (Germany)

States of the Proton in Chemistry
Angewandte Chemie was founded in 1888. In response to popular demand the International Edition in English of Angewandte Chemie began its appearance in January 1962 resulting in its establishment as a leading international publication. Rapid translation of the contents of Angewandte Chemie enables the International Edition to appear almost simultaneously with the German edition.
Each volume of Angewandte Chemie International Edition in English consists of twelve issues. The subscription rate for Volume 3,1964 and Volume 2,1963 is DM 80.00=\$20.00 plus postage each, and for Volume 1, 1962 DM 60.00= $\$ 15.00$ plus postage. Copies of all isstes from Volume 1 , No. 1 onwards are still available. On request we shall be glad to send a sample copy free of charge.

\section{Verlag Chemie, GmbH.}

Pappelallee 3

Weinheim/Bergstr., Germany

\section{Academic Press}

111 Fifth Avenue, New York 10003

Berkeley Square House, London, W.1. 